Case study

\title{
Chain of Archival Requirements. Usability of Digital Records in the Context of e-Services in Sweden
}

\author{
Erica Hellmer \\ Department of Information Systems and Technology \\ Mid Sweden University \\ Holmgatan 10, 85170 Sundsvall, Sweden \\ erica.hellmer@miun.se
}

\begin{abstract}
Summary
This paper presents an ongoing case study within the ISERV research project at Mid Sweden University, examining the process of changes in the records management process when paper-based turns digital and also examining the challenges in the change within the profession of the archival domain. The findings of this study will contribute to an understanding of the creation of sustainable eservices where the information will continue to be usable, with an archival requirement perspective over time.
\end{abstract}

Key words: digital records management, digital preservation, e-services, ISO 15489, ISO 40100, usability, accessibility

\section{Introduction}

E-government facilitates administration, making it more efficient, open, and more comfortable for both citizens as well as organizations. The EU eGovernment action plan 2016-2020 is accelerating the digital transformation of governments by suggesting principles with the purpose to coordinate the modernization of the new digital government, and to "modernize public administration, achieve cross-border interoperability and facilitate easy interaction with citizens"1.

Within Sweden, governments and municipalities endeavor to create and implement an efficient electronic government in order to provide public services to citizens and to create a digital records management. Along the rapid ongoing technical development and the continuing demand of service and use and reuse of information the development of e-services and e-archives is increasing. In the digital agenda of Sweden, one challenge is to have a digital records management that supports the organizations, but also a records management that includes the archival requirements. Nevertheless, e-services created today that in-

${ }^{1}$ European Commission (2016) p. 4 
clude, or will include, the profession of archivists or other specialists within the information domain are seldom created by the archivists themselves. Users, external and internal, of e-services are often elucidated as well as usability issues regarding the design of public e-services but rarely the accessibility and preservation of the information that these new e-services will handle. ${ }^{2}$

Changing from paper-based records management towards a digital records management creates challenges and also a changing role of the archivist or other information professionals in preserving the evidential value. The changing role also includes making access for present and future use when moving from the role of a guardian to actively intervene in the records creation process and shaping the collective and social memory. ${ }^{3}$

This ongoing case study is examining e-services created today with a usability and preservation perspective and also the new active role of information professionals. The process that will be studied is a new e-service that will be created by The Swedish Companies Registration Office (Bolagsverket) and focuses on managing digital financial information, in this case annual reports. By using the standard XBRL (ISO 40100), the former paper-based process of annual reports will turn digital. This is an initial study, and a part of the ISERV research project ${ }^{4}$, in examining the domain of e-services and will contribute to the creation of e-services with e-archive requirements.

\section{Research problem and questions}

New decisions regarding implementation of new techniques or new standards set demands on both current and future records management and records (re)usability.

The process of annual reports is today paper-based where different types of information in a variety of formats are submitted, controlled, scanned, and preserved. This process is to be computerized through a digital service. Examining the process of how this digital service will function in an authority which will create the digital service, and also examining the users of this service, will provide an ecological and representative case study where we gain insight in the construction of e-services. It is also relevant to examine the profession of the archival domain when the work process is changing.

\footnotetext{
${ }^{2}$ Goldkuhl G, Röstlinger, A (2010)

${ }^{3}$ Millar (2010)

${ }^{4}$ The main goal of ISERV research project is to develop prerequisites of the development of eservices and archival practices. The project is coordinated by the a research group at Mid Sweden University and will also be carried out with participants of the Västernorrland region The project focuses on the capturing, managing and reuse of information within organizations. https://www. miun.se/iserv/
} 
The primary research questions are the following:

- How is usability and preservation considered when paper-based records management turns digital?

- What does the use of new e-services implicate to the long term records management at The Swedish Companies Registration Office (Bolagsverket)?

- How is the role of information professionals affected?

Limited companies are obligated to annually report to The Swedish Companies Registration Office according to the annual accounts act (1995:2554). These reports include directors' reports, profit-and-loss accounts, balance sheets, and notes. ${ }^{5}$ An annual report is therefore not only one document and retaining a complete chain of information is relevant.

It is also relevant that the aggregation of records of an organization meet the recordkeeping requirements in order to provide links between records, i.e., meaning and evidence. A record's authenticity, integrity, and understandability derives from its relationships with other records, i.e., the aggregation of records. $^{6}$ Within the records management context, the international standard 15489-1:2016 provides guidelines to "ensure that authoritative evidence of business is created, captured, managed and made accessible to those who need it, for as long as it is required". ${ }^{7}$ The standard sets out requirements for records which are requirements for evidence of business activity. These records requirements are context-dependent, and may pertain to any records process, may apply to whole functions, industries or jurisdictions, and should be linked to particular functions, activities or work processes. According to the standard the processes for creating, capturing and managing records should be integrated to procedures, records systems and should be supported by policies. For ensuring continuing usability it is suggested in the standard to prepare a plan to enable continuing access and usability.

\section{Research design}

The design for this study is a qualitative case study consisting of semi structured interviews with key personnel at The Swedish Companies Registration Office with the purpose of collecting data of the process of the annual reports. Interviews with two limited company will also be carried out in order to gain knowledge regarding the work process, how and which information is structured when these annual reports is transferred to the Swedish Companies Registration Office. Today, limited companies prints, signs, and posts their annual reports to the Swedish Companies Registration Office. It is relevant to study the

\footnotetext{
${ }^{5}$ Annual accounts act (1995:2554)

${ }^{6}$ Hofman (2005)

${ }^{7}$ ISO 15489 (2016) p. VI
} 
whole chain of information in classical structure in recordkeeping i.e. when it is created, captured, organized and made accessible.

The study will follow the process of the new e-service at the Swedish Companies Registration Office from planning to implementation and ultimately do a reflection of the whole process. This initial study is investigating how the role of information professionals is affected by a new work process: focusing on both when the process of annual reports turns digital, but also what the use of the new e-service will implicate to the long term records management at The Swedish Companies Registration Office. As it is today, the process of annual reports is mostly paper-based and in an initial interview with an archivist at The Swedish Companies Registration Office it is described as outdated. However, the interviewee envisions that an implementation will simplify the re-usability, preservation, and open up for new functions. The interviewee ads further that it is of great importance to be able to reuse information both within The Swedish Companies Registration Office as well as outside of the authority. The international standard 15489-1: 2016 can be used as an audit tool, a checklist of the new digital work process at Bolagsverket.

Figure 1 shows a traditional records management with traditional steps of responsibilities and functions from creation to archives management. The figure is also inspired by the records continuum model, created by Frank Upward ${ }^{8}$, with a post-custodial perspective where the role of archivist are more active in the organizations where the records are created and used.

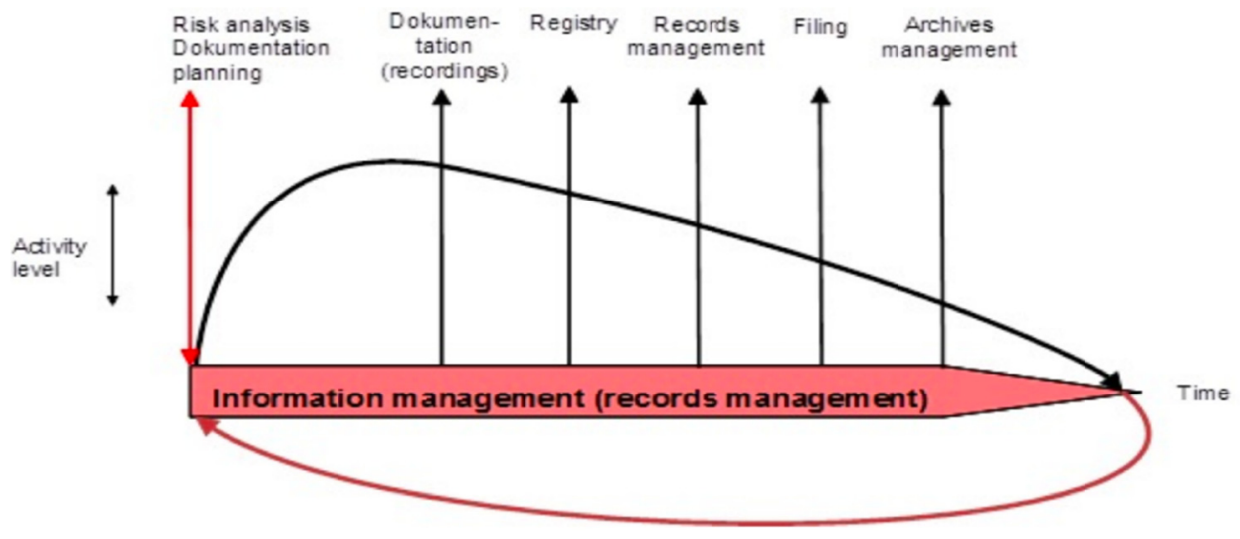

Figure 1. Components of digital information management

\footnotetext{
${ }^{8}$ Upward (1996)
} 
The continuum model can be used as a supporting process when evaluating and exploring the different steps in the recordkeeping process at The Swedish Companies Registration Office today and after the implementation of the digital service.

Records continuum thinking and practice has brought records managers and archivists under a "recordkeeping umbrella". It has focused on unifying and multiplying purposes and frameworks for accountable recordkeeping which may enable access to useable evidence of social and business activity. A records continuum approach enables partnerships with stakeholders in business and information domain. Previous collaborative partnership with records managers, archivists and standard setters resulted in standard development. There is an interest of collaboration with IT professionals, archivists, records managers, system managers or other stakeholders in order to develop coherent information architecture and metadata structures. ${ }^{9}$

\section{Preliminary results}

Results of this ongoing case study suggest that e-services created today need to be efficient, accessible, and reusable. It indicates a more dynamic and continuing records management that is opened and advocates reusability. When examining this digital service at The Swedish Companies Registration Office, which has a well-established and structured process in managing paper-based annual reports, it will open up for new ways to analyze and measure processes and records.

A preliminary observation regarding the profession of information professionals that handles, and will handle the information of the annual report through the eservice indicates a need of intern education regarding the understanding and development of e.g. metadata and making data searchable and accessible. It indicates that the profession of the archival domain can contribute with a proactive and holistic approach. In the context of the digital agenda and the modernization of the new digital government the ISERV research project will elucidate not only the practical way when developing new e-services and the active role of the archive profession but also whether archival principles do in fact apply.

${ }^{9}$ McKemmish, 1997 


\section{References}

Annual Accounts Act (1995:1554). Swedish code of statutes. Webpage: http://www.riksdagen.se/ sv/dokument-lagar/dokument/svensk-forfattningssamling/arsredovisningslag-19951554_sfs1995-1554 Retrieved at 19/5 2017

European Commission. Communication from the commission to the European parliament, the council, the European economic and social committee and the committee of the regions. EU eGovernment Action plan 2016-2020. Brussels, 19.4.2016. COM (2016) 179 Final.

Goldkuhl, G; Röstlinger, A. Development of public e-services - a method outline. // Paper accepted to the $7^{\text {th }}$ Scandinavian workshop on E-Government (SWEG-2010) January 27-28 2010, Örebro University

Hofman, H. The archive. // Archives: Recordkeeping in Society. McKemmish, S, Pigott, M, Reed, B, Upward, F. (eds). Wagga Wagga, NSW: Centre for Information Studies, Charles Sturt University. (2005)

International Organisation for Standardisation. Information and documentation - Records management - Part 1: Concepts and principles. 15489-1:2016.

McKemmish, S. Yesterday, today and tomorrow: a continuum of responsibility.// Proceedings of the Records Management Association of Australia 14 ${ }^{\text {th }}$ National Convention, 15-17 Sept 1997, RMAA Perth

Millar, L.A. Archives principles and practices. // Principles and practices in records management and archives. Series Editor: Geoffrey Yeo. (2010)

Upward, F. Structuring the Records Continuum - Part One: Postcustodial principles and properties. // First published in Archives and Manuscripts, 24 (2) (1996) 